\title{
Some Expected Mechanical Characteristics of Lunar Dust: A Geological View
}

\author{
Doug Rickman ${ }^{1}$ and Kenneth W. Street ${ }^{2}$ \\ ${ }^{1}$ National Space Science and Technology Center, NASA Marshall Space Flight Center, Huntsville, AL 35805 USA \\ ${ }^{2}$ Tribology and Surface Science, NASA Glenn Research Center, Cleveland, OH 44135 USA \\ 256-961-7889, doug.rickman@nasa.gov
}

\begin{abstract}
The engineering properties of the lunar regolith reflect aspects of the original parent rock and the consequences of hypervelocity meteor bombardment. Compared to the Earth the geologic nature of the lunar regolith is quite distinct. On scales relevant to machinery, heterogeneity with respect to size and composition is much higher. But the total range in composition is much more restricted. Both facts have implications for predictions of properties, such as abrasion, which will be required by design engineers for constructing equipment for lunar use. Abrasion is related to hardness and hardness is a commonly measured property for both minerals and engineering materials. Although different hardness scales are routinely employed for minerals and engineering materials, a significant amount of literature is available relating the two. In this paper we discuss how to relate hardness to abrasion for the design of lunar equipment. We also indicate how abundant the various mineral phases are and typical size distributions for lunar regolith.
\end{abstract}

Keywords: Lunar regolith, mineralogy, engineering materials, abrasion.

PACS: 89, 89.20.Bb.

\section{INTRODUCTION}

The initial composition of the lunar crust is believed (Wilhelms, McCauley, and Trask, 1987; Jolliff, et al., 2006; Heiken, Vaniman, and French, 1991) to have been dominated by intrusive igneous rock with an average composition in the range of norite (Le Maitre, 2005). Subsequent eruptive phases deposited basaltic materials as flows and in various other volcanic forms. The basaltic deposits form the mare (seas) of the Moon; the non-mare regions are termed the highlands. Hypervelocity impacts have largely destroyed all of the original crustal rock and some of the basaltic rock at the surface, producing a pervasive layer of shattered and altered residue. The resulting broken geologic material covering the surface of the Moon is termed regolith (Gary, McAfee, and Wolf, 1973). Except for some outcrops in or around the mare, all interaction people and equipment will have with the surface of the Moon will be with this regolith.

In the following we will consider just a few of the geologic characteristics of the regolith: sorting, distribution of particle sizes, and composition of the particles. Other geologic properties (such as particle shape and information about the fraction below $20 \mu \mathrm{m}$ ) are also of engineering interest but little specific information about the lunar material is currently available. Current and future research will address such deficiencies. The objective of this paper is to introduce the engineering design community to lunar geologic considerations that will govern choice of construction materials.

\section{Geology of the Lunar Regolith}

Energy from a hypervelocity impact is distributed into the surface of the Moon through a combination of processes. For example material is physically moved, heated, and broken. A result of movement is discussed below under 
Sorting. Heating is so intense as to melt some of the material, the results of which are discussed below. Breaking results in comminution of the initial rock to ever smaller particle sizes.

\section{Particle Size}

Counter acting the comminution is the thermal energy derived either directly from the impact or indirectly from seismic motion of the rock. Both can be so intense as to either completely melt the material or to cause welding of particles. The former, impact melts, can form either glass if chilling is rapid enough, or it can crystallize. The latter are termed breccias and can be either very solid rocks or can be highly friable.

The products of micrometeorite impact are usually considered as a special case. As with larger impactors some of the energy breaks existing particles and some welds particles together. The result is hypothesized to be a trend to slowly ablate large particles, i.e. rocks, the conversion of mineral grains to glass, and the welding together of submillimeter particles into something called agglutinates.

The lunar surface has had no significant geologic process of renewal for several billion years. Thus the net result of the continuing meteor bombardment has been to grind the surface of the Moon into a mixture of fragments ranging in size from the nanoscopic to large blocks of rock. This mixture is thought to be meters deep over virtually all of the lunar surface. For samples of the fine grained regolith returned by the Apollo missions typical average particle sizes vary from approximately 30 to 100 micrometers.

\section{Sorting}

On the Earth, all particles will be exposed to a fluid, such as water or air, and to gravity when created, moved and deposited. Consequently, through a host of physical processes terrestrial particles tend to become sorted based on size, shape and composition. None of these segregating processes operate in a vacuum. Energy input on the lunar surface, if sufficient to cause particle motion, can cause mixing but not sorting.

Lunar processes which are spatially uneven can cause differences which superficially resemble sorting. For example micrometeorites can only impact the upper few millimeters of the regolith. Thus, the regolith at the immediate surface of the Moon will tend to have more agglutinates than deeper samples. In fact this tendency is used to provide a relative age of the surface (Papike, Ryder and Shear, 1998).

Consequently, designers can generally assume the regolith their systems will interact with is highly heterogeneous. Compared to terrestrial materials it is heterogeneous in both particle size distribution and particle composition. Engineers can expect that for any reasonable sized sample taken from the top few meters of the regolith it is possible, and even probable to have particles of all size ranges and any lunar component in the sample. There are variations in the size distributions and composition from sample to sample, but functionally all are likely to be present to some extent in the distribution.

\section{Particle Composition}

The composition of the lunar dust fraction, material $<20 \mu \mathrm{m}$, is currently less well characterized. There are some aspects of these particles, such as the presence of nanoscopic $\mathrm{Fe}$ and vapor deposited rims, which may or may not be important. However, until the dust fraction is better characterized statements about the engineering significance involving these aspects are rather speculative. If we assume the dust fraction is generically analogous to the $20-$ $1000 \mu \mathrm{m}$ material we can make some reasonable predictions. Therefore, in the following discussion the reader should remember the relevant data generally has been obtained from particles courser than $20 \mu \mathrm{m}$.

For mechanical purposes the composition of the regolith can be considered to contain four major constituents in varying amounts: lithic fragments, minerals, glasses and agglutinates. Lithic fragments, which are pieces of rock, are dominated by breccias and shock welded regolith clasts. These vary in mechanical strength from extremely friable to highly indurated. The grain size can also be unusually small, for example $0.2 \mathrm{~mm}$ for the total particle of rock! The non-breccia clasts are pieces of various mafic intrusive rocks, such as norite and anorthosite, and basalt. 
There are approximately 100 minerals known from the Moon, some of which were first identified in Lunar samples. This compares to well over 2000 terrestrial minerals. (see Gaines, et al., 1997 for variations relating to Dana \#, which is a mineral's unique identifier expressing chemical and crystallographic relationships. Minerals which are very similar will differ only in the last figure, for example, Bytownite versus Labradorite.) Lunar mineralogy is dominated by a very limited number of species. Table 1 shows the minerals chosen by the Lunar Simulant team at Marshall Space Flight Center determined to be sufficient to describe the regolith. Glass has been produced by impact melts and micrometeorites, as noted above. It has also been produced by volcanic eruptions. In either case the glass is a complex, silicate dominated mixture containing variable amounts of $\mathrm{Mg}, \mathrm{Fe}, \mathrm{Ca}, \mathrm{Al}$ and other elements. The fourth major regolith constituent, agglutinates, are a mixture of glass, lithic fragments and mineral particles stuck together as friable reentrant particles.

The recognition of four constituents is very important for macroscopic considerations. At microscopic scales the situation can be simplified. Rocks are aggregates of minerals. The agglutinates are glass plus minerals. Thus, at microscopic scales the lunar regolith can be considered to be particles which are combinations of minerals and silicate glass. A mineral is a naturally occurring substance that has a characteristic, limited chemical composition and a highly ordered atomic structure. Therefore the range of each mineral's properties is limited and the properties of a mineral are basically independent of the mineral's source, lunar or terrestrial.

\section{Hardness And Abrasion}

Geologists use the relative hardness of minerals and the way the minerals break as major clues to the identification of minerals in hand samples. Manuals of mineralogy provide this information as basic data. Hardness is discussed at length below. The failure mode is subdivided into two categories, along preferential orientations controlled by crystallography or independent of orientation. The former, termed cleavage, is characterized by the perfection of the planar surface formed by the break and the orientation with respect to the crystal lattice. Particles of minerals with perfect or good cleavage tend to break into fragments more readily than minerals lacking cleavage. Thus lunar regolith shows a very distinct and regular variation in composition as a function of particle size. Smaller particles have a higher probability of being one of the feldspars; anorthite, bytownite and labradorite. A break which is not oriented with respect to crystal orientation is termed fracture. Fractures are observed to fall into a limited number of patterns. Of special interest to someone interested in abrasion are those minerals which have a conchoidal fracture. Glass also has conchoidal fracture and is well known for its tendency to make sharp, serrated edges. This is what any material with conchoidal fracture will tend to do.

\section{Hardness Scales}

Hardness is generally defined as the resistance to plastic deformation. Minerals tend to be crystalline and friable in nature and consequently their hardness has traditionally been measured by a scratch test that compares the ability of the mineral in question to scratch (or be scratched) by a series of standard minerals, which are incrementally harder, the Mohs scale. First introduced by Friedrich Mohs in 1822, ten minerals ranging from soft minerals like talc (Mohs hardness $=1$ ) to hard materials like diamond (Mohs hardness $=10$ ) are used as standards by which to compare relative hardness of other materials. Metals on the other hand are less friable and more ductile making them suitable to indentation testing. Hardness scales proposed for metals based on indentation include Brinell (1900), Vickers (circa 1920), Knoop (1939) and Rockwell (1919) which vary by indenter shape and how the indentation is performed. These indentation scales provide comparable information about metals and the scales have been correlated. With the exception of the hardness value for diamond, a plot of logarithm of hardness (Vickers or Knoop) in $\mathrm{Kg} / \mathrm{mm}^{2}$ versus Mohs hardness yields a linear plot (Tabor, 1954; Tabor, 1970) with a slope of 1.6. In this manner, scratch hardness of lunar minerals can be directly related to Knoop indentation hardness of construction materials.

\section{Relating Hardness Scales}

Figure 1 relates Mohs to Knoop hardness scales. As the Knoop, KHNn (Knoop Hardness Number, where $\mathrm{n}$ is the applied load), Vickers, HVn (Vickers Hardness where $\mathrm{n}$ is the applied load) and Brinell, HBn, (Brinell Hardness where $\mathrm{n}$ is the applied load) scales are all based on direct indentation, they yield hardness values close to one another 
TABLE 1. Significant Lunar Minerals. \%: A-abundant, M-major, m-minor, t-trace.

\begin{tabular}{|c|c|c|c|c|c|c|c|}
\hline Mineral & Dana \# & Mohs & $\begin{array}{l}\text { Specific } \\
\text { Gravity }\end{array}$ & Mode: Cleavage & Mode: Fracture & $\%$ & Chemical Composition \\
\hline Anorthite & 76.1.3.6 & 6 & 2.75 & $\{001\}$ perfect, $\{010\}$ good & Conchoidal to uneven fracture; brittle & A & $\mathrm{CaAl}_{2} \mathrm{Si}_{2} \mathrm{O}_{8}$ \\
\hline Bytownite & 76.1 .3 .5 & $6.0-6.5$ & 2.73 & $\{001\}$ perfect, $\{010\}$ good & Conchoidal to uneven fracture; brittle & M & $(\mathrm{Ca}, \mathrm{Na})(\mathrm{Si}, \mathrm{Al})_{4} \mathrm{O}_{8}$ \\
\hline Labradorite & 76.1.3.4 & 7 & 2.71 & $\{001\}$ perfect, $\{010\}$ good & Conchoidal to uneven fracture; brittle & M & $(\mathrm{Ca}, \mathrm{Na})(\mathrm{Si}, \mathrm{Al})_{4} \mathrm{O}_{8}$ \\
\hline Olivine & 51.3 .1 & $6.5-7.0$ & - & - & - & M & $(\mathrm{Mg}, \mathrm{Fe})_{2} \mathrm{SiO}_{4}$ \\
\hline Fayalite & 51.3.1.1 & $6.5-7.0$ & 4.39 & $\begin{array}{l}\{010\} \text { moderate, }\{100\} \text { weak } \\
\{100\},\{010\} \text { indistinct to good; }\end{array}$ & Conchoidal & - & $\mathrm{Fe}_{2} \mathrm{SiO}_{4}$ \\
\hline Forsterite & 51.3 .1 .2 & $6.5-7.0$ & 3.24 & $\{001\}$ poor to fair & Conchoidal & - & $\mathrm{Mg}_{2} \mathrm{SiO}_{4}$ \\
\hline Clinoenstatite & 65.1 .1 .1 & $5.0-6.0$ & 3.4 & $\{110\}$ good to perfect & Brittle & M & $\mathrm{Mg}_{2}\left[\mathrm{Si}_{2} \mathrm{O}_{6}\right]$ \\
\hline Pigeonite & 65.1 .1 .4 & 6 & 3.3 & $\{110\}$ perfect & Conchoidal to uneven fracture; brittle & M & $\left(\mathrm{Mg}, \mathrm{Fe}^{+2}, \mathrm{Ca}\right)_{2}\left[\mathrm{Si}_{2} \mathrm{O}_{6}\right]$ \\
\hline Hedenbergite & $65.1 .3 \mathrm{a} .2$ & 6 & 3.5 & $\{110\}$ good & Conchoidal to uneven fracture & M & $\mathrm{CaFe}^{+2}\left[\mathrm{Si}_{2} \mathrm{O}_{6}\right]$ \\
\hline Augite & $65.1 .3 \mathrm{a} .3$ & $5.5-6.0$ & 3.3 & $\{110\}$ good & Uneven & M & $(\mathrm{Ca}, \mathrm{Na})(\mathrm{Mg}, \mathrm{Fe}, \mathrm{Al}, \mathrm{Ti})\left[(\mathrm{Si}, \mathrm{Al})_{2} \mathrm{O}_{6}\right]$ \\
\hline Enstatite & 65.1 .2 .1 & $5.0-6.0$ & 3.4 & $\{210\}$ good to perfect & Conchoidal & A & $\mathrm{Mg}_{2}\left[\mathrm{Si}_{2} \mathrm{O}_{6}\right]$ \\
\hline Spinel & 7.2.1.1 & 7.5-8.0 & 3.56 & No cleavage & Conchoidal & $\mathrm{m}$ & $\mathrm{MgAl}_{2} \mathrm{O}_{4}$ \\
\hline Hercynite & 7.2.1.3 & $7.5-8$ & 3.93 & No cleavage & Uneven & $\mathrm{m}$ & $\mathrm{Fe}^{+2} \mathrm{Al}_{2} \mathrm{O}_{4}$ \\
\hline Ulvospinel & 7.2.5.2 & $5.5-6.0$ & 4.7 & No cleavage & Uneven & $\mathrm{m}$ & $\mathrm{TiFe}_{2}^{+2} \mathrm{O}_{4}$ \\
\hline Chromite & 7.2.3.3 & 5.5 & 4.7 & No cleavage & Uneven & $\mathrm{m}$ & $\mathrm{Fe}^{+2} \mathrm{Cr}_{2} \mathrm{O}_{4}$ \\
\hline Troilite & 2.8.9.1 & 4 & 4.75 & No cleavage & Uneven & $\mathrm{t}$ & $\mathrm{FeS}$ \\
\hline Whitlockite & 38.3.4.1 & 5 & 3.12 & No cleavage & Uneven to sub-conchoidal & $\mathrm{t}$ & $\mathrm{Ca}_{9}\left(\mathrm{Mg}, \mathrm{Fe}^{+2}\right)\left(\mathrm{PO}_{4}\right)_{6}\left(\mathrm{PO}_{3} \mathrm{OH}\right)$ \\
\hline Apatite & 41.8.1.0 & 5 & 3.19 & No cleavage & Uneven to conchoidal & $\mathrm{t}$ & $\mathrm{Ca}_{5}\left(\mathrm{PO}_{4}\right)_{3}(\mathrm{OH}, \mathrm{F}, \mathrm{Cl})$ \\
\hline Ilmenite & 4.3.5.1 & 5.5 & 4.72 & No cleavage & Conchoidal & $\mathrm{m}$ & $\mathrm{Fe}^{+2} \mathrm{TiO}_{3}$ \\
\hline Native Iron & 2.9.1.1 & 4.5 & 7.87 & $\{001\}$ Imperfect to fair & Hackly & $\mathrm{t}$ & $\mathrm{Fe}$ \\
\hline
\end{tabular}




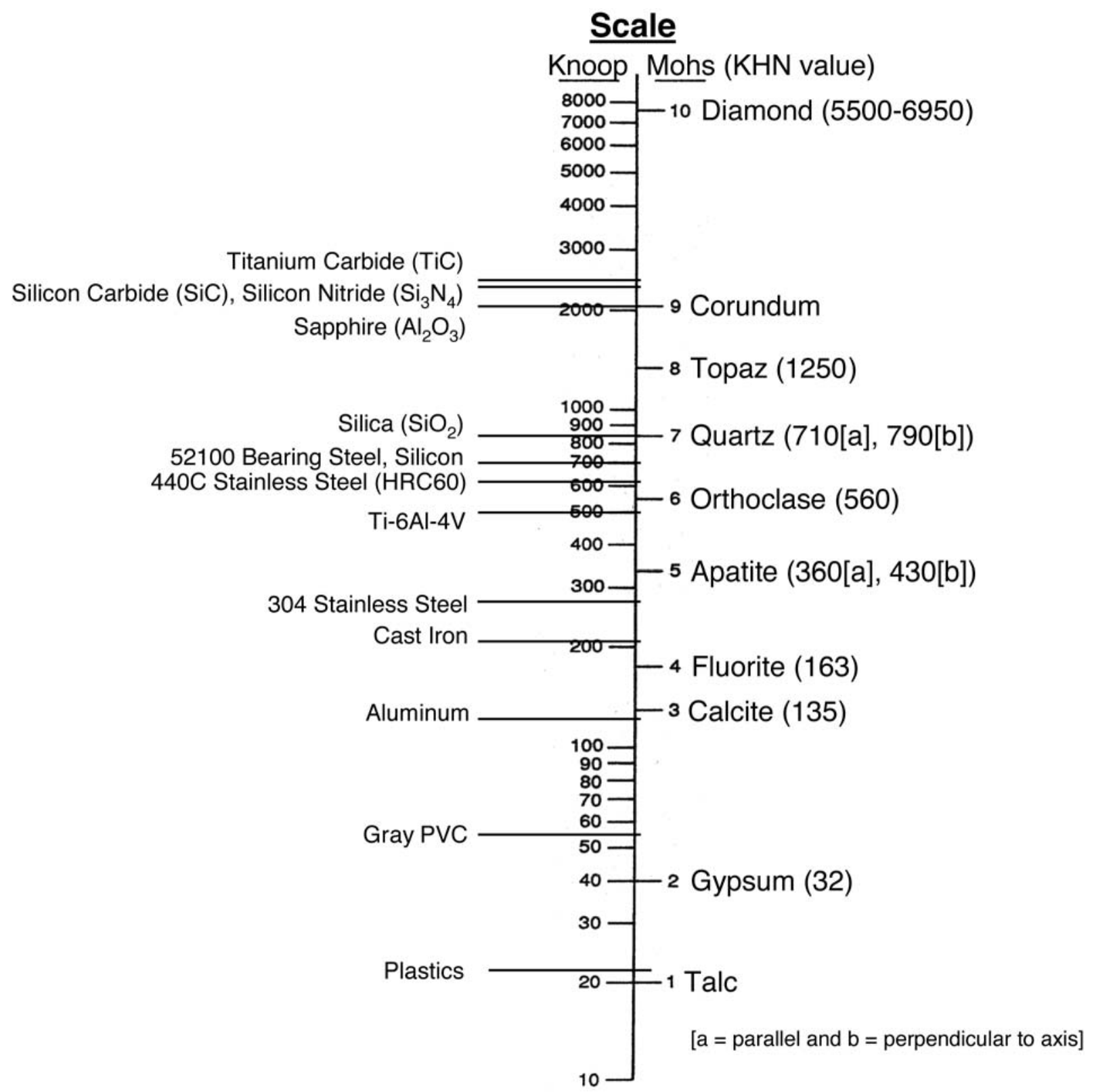

FIGURE 1. Comparison of Mohs and Knoop Hardness.

in most cases. Brinell values are slightly lower than those of Vickers whereas Knoop are slightly greater than Vickers. The minerals used for the Mohs scale are included for reference. The values in the literature for some minerals, such as diamond show a great amount of variation due to variability in composition and experimental determinations. Further variation occurs for anisotropic materials like quartz and apatite where the hardness measured is related to the crystal structure. The same can be said for the values for the commonly used construction materials listed on the Knoop side of the scale. From figure 1, it is apparent that some of the minerals will do significant abrasive wear to commonly used materials.

Rockwell scales values (HRB and HRC) are approximately related to the other indenter scale values as appearing in table 2. The Rockwell scales are unlike the other scales in that two forces are applied during the indentation, an initial minor load applied until equilibrium is achieved, followed by a major load until equilibrium is reestablished. 
It should be noted that extensive comparison tables, ASME-140, are available (ASTM International, 2007) but it must be stressed that these conversions are only approximate because of the differences in applied load between and within each method as well as differences in indenter materials and geometry. Direct application of these values is further complicated by the lack of specification of the applied load used in determining the values reported in the literature (as in Fig 1, which is partially abstracted from the literature (Blau, 1992; Tylczak, 1992; Jacobsson, et al., 1992)).

\section{Relating Hardness to Abrasion}

Both of these terms are relative to condition and application of the term. Polishing is a term for abrading a surface smooth enough that light will be specularly reflected, which occurs when surface irregularities are much smaller than the wavelength of light. For example, in order for specular reflection to occur in the visible (blue, $400 \mathrm{~nm}$ light, is the shortest wavelength), the surface would have to have surface irregularities on the order of $<200 \mathrm{~nm}$. Typically, this type of polished surface can be achieved with a 2 micrometer grit abrasive (Samuels, 1992). While having highly polished surfaces is conducive to having tribologically contacting surfaces run smoothly in terrestrial environments, it poses another concern in the lunar environment. For example, many lubricants have greater lifetimes when the surfaces they are lubricating are metal oxides. Polishing this thin oxide layer away leaving the nascent metal as the contacting surface in an environment where the oxide layer will not be regenerated often has a significant detrimental impact on lubricant lifetime. As the size of the abrasive grit becomes larger, abrasive wear of the metals becomes such that close tolerances can no longer be maintained within a tribological contact. At still larger grit, mechanisms may jam causing immediate failure. The general relationship between hardness and wear is that abrasive wear will begin when the hardness of the grit only slightly exceeds the hardness value of the construction material. Abrasion continues to become more pronounced to the point at which the hardness of the abrasive approaches a value of 1.5 times that of the construction material where the ability to abrade levels off (Tylczak, 1992).

Severity of abrasion for metals, ceramics and other regular solid materials can be gauged by comparing the hardness values of the abrasives, the lunar regolith constituents in Table 1, to the engineering materials in Figure 1, where necessary using the relationship described by Tabor (Tabor, 1954 and Tabor, 1970) or standard correlation charts (ASTM International, 2007; England, 2007; Leco Corporation, 2007). Polymeric materials like fabrics and polyacrylic plate will also be used, for example in EVA suits, but discussion of these materials is beyond the scope of this paper. Many polymeric materials have low hardness values and will be abraded by almost everything encountered in the lunar environment. A redeeming feature may be that the hard abrasive materials will imbed in, rather than scratch or abrade these materials thereby partially neutralizing their effect.

Table 2. Approximate Correlation Between Hardness Scales.

\begin{tabular}{|c|c|c|c|c|c|c|}
\hline \multicolumn{7}{|c|}{ Hardness Values (load) } \\
\hline HV & HB & HB & HRB & HRC & KHN & $\begin{array}{c}\text { KHN } \\
(1 \mathrm{~kg})\end{array}$ \\
\hline 1865 & - & - & - & 80 & - & - \\
\hline 832 & - & 739 & - & 65 & - & - \\
\hline 595 & - & 560 & 120 & 55 & 840 & 605 \\
\hline 254 & 201 & 240 & 100 & 23 & 376 & 250 \\
\hline 156 & 133 & 153 & 81 & 0 & 223 & 145 \\
\hline 70 & 53 & - & 0 & - & - & 60 \\
\hline
\end{tabular}

\section{CONCLUSION}

We believe that many aspects of current and future engineering debate can and must be constrained by an understanding of the regolith. This preliminary information, based solely on very basic lunar geology, can be useful for initial work on habitat construction, moving mechanical assemblies, seals, mineral processing, and other component design. This paper provides a compilation of the relevant geologic data and combines it with selected 
engineering properties for a suite of engineering materials, and assumes dust seals cannot be perfect or may not be possible in some applications. The feldspars; anorthite, bytownite and labradorite, which are abundant on the Moon, are approximately as hard as steels and will break down into smaller particles relatively easy because of perfect cleavage. The olivine minerals on the other hand will not break as easily and the fracture surfaces will be noticeably sharp. An industrial minerals geologist would suggest that olivine will behave much like the garnet abrasive in sandpaper, i.e. as it wears the particle of garnet tends to break and in so doing creates new, sharp edges. Other minerals, such as spinel, while minor in abundance are very tough, very hard and break with sharp edges. It is distinctly possible that mechanical processes could unintentionally concentrate such a mineral phase within the equipment with the consequence of unexpectedly rapid wear of the components. It is possible that small amounts of abrasive materials, e.g. spinels, may do $95 \%$ of the abrasive damage in some situations. The fact that spinel may constitute $0.1 \%$ of the top $20 \mathrm{~cm}$ of the Moon implies an enormous reservoir of abrasive on the lunar surface.

\section{ACKNOWLEDGMENTS}

The authors wish to thank J.R. Skok, now of Brown University and Ashley Boudreaux for their assistance in compiling and developing data from the literature on mineral properties and the relative abundance of lunar minerals.

\section{REFERENCES}

ASTM International, Standard Hardness Conversion Tables for Metals Relationship Among Brinell Hardness, Vickers Hardness, Rockwell Hardness, Superficial Hardness, Knoop Hardness, and Scleroscope Hardness, ASTM E 140, ASTM International West Conshohocken, PA, 2007.

Blau, P.J., in ASM Handbook, 18, Friction, Lubrication, and Wear Technology, S.D. Henry ed., 1992 ASM

International, Cleveland, OH, 1992, p. 416.

England, G., "Hardness Testing," http://www.gordonengland.co.uk/hardness/, accessed August 24, 2007.

Gaines, R.V., Skinner, H.C.W., Foord, E.E., Mason, B., and Rosenzweig A., Dana's New Mineralogy: The System of

Mineralogy of James Dwight Dana and Edward Salisbury Dana, 8th ed. Wiley, New York, 1997.

Gary, M., McAfee, R., and Wolf, C.L., Glossary of Geology. American Geological Institute, Washington, 1973.

Heiken, G., Vaniman, D., and French, B.M., Lunar Sourcebook: A User's Guide to the Moon. Cambridge University Press, Cambridge [England] ; New York, 1991.

Jacobsson, S., Olsson, M., Hedenqvist P., and Vingsbo, O., "Scratch Testing," in ASM Handbook, 18, Friction,

Lubrication, and Wear Technology, edited by S.D. Henry, ASM International, Cleveland, OH, 1992, p. 433.

Jolliff, B.L., Wieczorek M.A., Shearer C.K., and Neal C.R., "New Views of the Moon. Reviews in Mineralogy and

Geochemistry," 60, Mineralogical Society of America, Chantilly, Va., 2006.

Leco Corporation, "Hardness Testing," (2006), http://www.leco.com/resources/met_tips/met_tip9.pdf, accessed August $24,2007$.

Le Maitre, R.W. and International Union of Geological Sciences. Subcommission on the Systematics of Igneous Rocks., Igneous

Rrocks: A Classification and Glossary of Terms: Recommendations of the International Union of Geological Sciences,

Subcommission on the Systematics of Igneous Rocks, 2nd ed. Cambridge University Press, Cambridge, U.K. ; New York, 2005.

Papike, J.J., Ryder, G., and Shearer, C.K., in Reviews in Mineralogy, 36: Planetary materials, edited by J.J. Papike,

Mineralogical Society of America, Washington, D. C., 1998, pp. 234.

Samuels, L.E., "Polishing Wear," in ASM Handbook, 18, Friction, Lubrication, and Wear Technology, edited by S.D.

Henry, ASM International, Cleveland, OH, 1992, pp. 191-193.

Tabor, D., Mohs's Hardness Scale - A Physical Interpretation, Proc. Phys. Soc. B 67, 249-257(1954).

Tabor, D., The Hardness of Solids, Review of Physics in Technology 1, 145-79 (1970), http://www.iop.org/EJ/article/0034 6683/1/3/I01/ptv1i3p145.pdf, accessed August 24, 2007.

Tylczak, J.H., “Abrasive Wear,” in ASM Handbook, 18, Friction, Lubrication, and Wear Technology, edited by S.D.

Henry, ASM International, Cleveland, OH, 1992, pp. 187-189.

Wilhelms, D.E., McCauley, J.F., and Trask, N.J., The geologic history of the moon. U.S. Geological Survey professional paper 1348, Unites States Geological Survey, Dept. of the Interior, Washington D.C., 1987. 